\title{
EL CHAMAMÉ: CONSTRUYENDO UN SIGNIFICADO HOY EN BUENOS AIRES Y EL CONURBANO BONAERENSE.
}

\author{
Sayuri Raigoza Rivera ${ }^{1}$
}

\section{Introducción}

Este artículo intenta explorar la manera en que los practicantes de Chamamé (músicos y no músicos), construyen y dan significado al género a través de los encuentros que realizan asiduamente cada semana en diferentes lugares de Buenos Aires. Cuando hacemos referencia a significado, nos referimos al sentido que los actores le otorgan al hecho musical chamamecero ${ }^{2}$-integrado por música y baile- . $^{-}$

El Chamamé ${ }^{3}$ ha acompañado a los migrantes provincianos desde sus localidades originarias hasta las grandes ciudades de Rosario y Buenos Aires, desde los años 1930 y más pronunciadamente desde 1950. De origen principalmente correntino, el Chamamé cubre el área de dicha provincia y penetra en el oriente chaqueño, Formosa, Misiones, Entre Ríos y se implanta en Santa Fe, Conurbano Bonaerense y la capital del país; acompaña a los migrantes internos que fueron a trabajar en la construcción, el puerto, el ferrocarril y la industria, además de los servicios públicos y agencias estatales como fuerzas armadas y de seguridad. Posteriormente, el Chamamé

\footnotetext{
${ }^{1}$ Universidad Nacional de San Martín-Instituto de Altos Estudios Sociales/Instituto de Estudios Económicos y Sociales, Becaria Conicet, Argentina.

${ }^{2}$ Para la elaboración de este texto, tomé como punto de partida el trabajo de campo que empecé desde junio de 2008 para la realización de la tesis de maestría en antropología social y que aun se encuentra en proceso de escritura.

Según Pérez Bugallo se trata de una expresión musical íntimamente emparentada con el gato, la chacarera, la zamba, el escondido, etc. que posee la misma - cuando no mayor - profundidad cronológica que muchas especies de esa gran familia. Fundamenta su posición en la dirección Perú-Paraguay de las corrientes colonizadoras, la llegada de los Jesuitas al Paraguay - desde Perú - y la introducción del romancero español (versos de 16 sílabas rimando entre sí en formas asonantes y divididas en dos hemistiquios de 8 sílabas cada uno) también desde Perú. El sur de Misiones y parte del este de Formosa participan de su vigencia aunque aquí ya comparten posiciones con la polka y las especies secundarias emparentadas directamente con la misma (galopa, guarania, etc.). Chaco es la provincia que sigue a Corrientes en cuanto a su difusión, debido principalmente al éxodo de correntinos hacia los algodonales y obrajes chaqueños en busca de trabajo y su afincamiento definitivo ha provocado un desplazamiento hacia el este, del área del chamamé y prácticamente los estratos populares rurales de las dos provincias que responden a la pauta folklórica guaranítica son los portadores más importantes de esta expresión. La proyección del chamamé en escala nacional producida por una preferencia general hacia los motivos musicales guaraníticos en los medios urbanos, hecho iniciado hace ya varios años, crece en intensidad y la difusión de composiciones lírico musicales inspiradas en los ritmos del litoral argentino podrían provocar, como consecuencia del movimiento provincias - metrópolis - provincias, un ensanchamiento o revitalización del chamamé en áreas marginales a la región donde tiene su ámbito natural y efectivo, por el prestigio que le otorga la metrópoli convirtiéndolo en moda nacional. (Pérez Bugallo, 1996)
} 
siguió los pasos de los "litoraleños" -hasta Cuyo y provincias patagónicas-, a los obradores, las viñas y los distritos mineros. Estas observaciones dirigen la mirada hacia dos cuestiones: la clase social y la región musical.

Hasta mediados de 1980, el Chamamé era un fuerte indicador de grupos populares de origen migratorio, pero comenzó a ingresar a los repertorios de sectores medios y autodenominados "progresistas" con su incorporación por parte de músicos reconocidos por su calidad y trayectoria política como, por ejemplo, Mercedes Sosa, Teresa Parodi y Antonio Tarragó Ros (h.). El Chamamé comenzó a ser objeto de ensayos de fusión, recreación y a presentarse en teatros centrales capitalinos y de las grandes ciudades. Además, no sólo ingresó en zonas ignotas para este género sino que se fue delineando de cara a otros géneros que lo colindaban inicialmente, como la Chacarera del centro y noroeste del país, irradiada desde Santiago del Estero, junto con la Polka y el Chotis de la música euro-oriental en la provincia de Misiones.

En los barrios periféricos de la Ciudad de Buenos Aires, asiduamente tienen lugar encuentros de migrantes provenientes en su mayoría de distintas provincias del nordeste argentino (Corrientes, Entre Ríos y Misiones), así como también de Santa Fe, Santiago del Estero y Chaco, convocados por la práctica del Chamamé (Cragnolini 2000:143). Este género "tradicional" de fuerte raigambre en la población proveniente de las zonas mencionadas, ha producido en las últimas seis décadas un movimiento cultural amplio en el que se conjugan la dinámica de producción y difusión masivas inserción en la industria discográfica, radios "comunitarias", circuitos de salones de baile comerciales- con modos de interacción grupal que los actores significan como "tradicionales". Tal movimiento propició el desarrollo de distintos estilos y regionalismos tanto a nivel vocal-instrumental como del baile.

Considerando que las manifestaciones o prácticas alrededor de la música y el baile condensan significados fundamentales, que permiten comprender la forma en que las personas se relacionan y su sociocosmología, este artículo intenta analizar a través de la práctica del Chamamé (música y baile) en Buenos Aires, algunos aspectos que permitan entender el modo en que los actores significan el género. La importancia de la cualificación debe acompañar la idea de que las identidades están en proceso de construcción, que pueden ser abiertas, múltiples y contradictorias y que involucran -al menos en parte- un hacer performativo, estando discursivamente construidas, sin que eso implique que sean solo discurso (Briones, 2006: 132). A partir de esta idea trataremos de comprender la existencia de una dimensión de selección qué, aunque no 
puede ser separada de la carga polivalente que contiene "identidad" (Brubaker y Cooper, 2002), merece tener un acercamiento. En este sentido la práctica del Chamamé adquiere significación como proceso social y no como identidad básica (Giorgis 2004:14).

Hablar de Chamamé no entraña una mera postal de los "pagos de origen”, ni una rémora del fenómeno migratorio rural-urbano y provinciano-capitalino de la Argentina. En esta investigación, el género del Chamamé se reconoce como práctica musical inscrito en relaciones sociales de comienzos del siglo XXI.

La migración de los habitantes de la provincia de Corrientes hacia Buenos Aires empieza a surgir en la primera mitad del siglo XX, haciendo que el Chamamé inicie su expansión con el arribo a la Capital Federal de los músicos correntinos. La difusión radial por entonces (década del '40), marcaba los rumbos de todo lo que fuera música del litoral. Con posterioridad y enmarcado en este proceso de migración interna iniciado años atrás (el éxodo correntino hacia Buenos Aires, en busca de mejoras económicas), surgen las "bailantas" como punto de encuentro y nostálgicas recordaciones del terruño natal. Esto en primera instancia permite que la danza del Chamamé se sume a estos lugares y que poco a poco con el tiempo se constituyan como sitios de reunión regular de la práctica chamamecera.

En consonancia, las identidades culturales vienen de alguna parte, tienen historia, pero, como todo lo que es histórico sufre una transformación constante (Hall, 2003: 252), las identidades lejos de estar eternamente fijas en un pasado esencializado, están sujetas al continuo "juego" de la historia, la cultura y el poder. Para el caso del Chamamé -género que en la constitución del Estado Nacional se excluye del folclore-, la idea de "Formación nacional" construida sobre la alteridad -el terror étnico argentino-, se establece entre las fronteras de música y lo que es ideológicamente aceptado. Lo aceptable y valorable de un género musical está en parte relacionado a la manera como se constituyo históricamente; es decir, la historia de un género musical determina no solo un marco estético de definición sonora, sino también un marco valorativo del género mismo (Ochoa, 2003a).

La eliminación de la diferencia en la conformación de los Estados Nacionales y en especial el argentino, plasmó una ideología a través de los límites de lo que se consideró representante de los "paisajes sonoros" del país, borrando las marcas de la 
diferencia estilística ${ }^{4}$; para el caso del Chamamé, el arraigo con el factor étnico lo sumerge en la exclusión, al no considerarlo folclore nacional (Cragnolini, 1999). Si bien éste trabajo intenta dar cuenta de cómo los practicantes de Chamamé hoy significan el género, es importante enmarcar o al menos vislumbrar la carga histórica que contiene la música como una coextención de un proyecto nacional que se refleja en las prácticas que realizan los denominados "cabecita negra". En el momento de la migración a Buenos Aires, se presentan dinámicas de tensión que actualmente se encuentran vigentes al considerar o asociar a la práctica chamamecera (baile y música) con lo "popular" con lo "negro".

\section{Caracterizando el campo}

Describiremos el campo de la práctica del Chamamé, tomando en cuenta los ensayos, presentaciones y festivales que constituyen espacios en los que se refuerzan mecanismos de articulación. Es pertinente señalar la labor del área cultural de la Casa de la provincia de Corrientes, abordando la relación existente entre esta institución, los grupos musicales de Chamamé y demás centros de residentes correntinos constituidos en su gran mayoría en el Conurbano Bonaerense ${ }^{5}$. Esta institución realiza labores de acción sociocultural, como la organización de eventos y muestras, programas de extensión y sensibilización, difundiendo información, ofreciendo talleres de Chamamé,

\footnotetext{
${ }^{4}$ En varios casos de las músicas folclóricas del cono sur, hubo procesos claros de homogeneización: es decir de favorecer la semejanza a costa de la diferencia. Antes de que se convirtiesen en géneros nacionales, era posible identificar una multiplicidad de formas de la Cueca, del Pasillo y del Bambuco. Pero una vez que pasaron del terreno local al nacional se eliminaron las diferencias estilísticas no deseables. Esto implica, por una parte un proceso compositivo: hay una forma musical del género que va a ser la más valida; hay una estética que se fija como la apropiada (Ochoa, 2003b).

${ }^{5}$ La investigación que se está llevando a cabo, inicialmente empezó a construir el campo desde la localidad de Rafael Castillo ubicada en el partido de la Matanza con una superficie de $14.250 \mathrm{Km} 2$ y Según el último Censo Nacional de Población, Hogares y Vivienda el total de población en el año 2001 era de 100.964 habitantes. Esta localidad se encuentra embarcada en un proceso social y cultural que presenta, a la observación preliminar realizada, importantes tensiones y peculiaridades entre las que podría decirse que la misma complejidad polifónica de estratos culturales y estructurales de las músicas que están en el punto de partida, se constituyen como reserva de sentidos alternativamente jerarquizados por los receptores de distinta proveniencia. En efecto, cada uno realiza lecturas selectivas del conjunto, filtrando franjas e iluminando sectores. En el distrito del Conurbano más poblado y sexta "provincia" argentina, en una localidad de fuerte presencia migratoria argentina y extranjera (paraguaya) que fue alternativamente permeada por la esperanza del pleno empleo y la movilidad social, la proliferación del hormigón, la ocupación de tierras, el piquete y los planes sociales, la hiperinflación, el eventual regreso o re-emigración a las provincias, y la nueva esperanza de la estabilidad. Según nuestras primeras entradas en campo los lugares donde se práctica el Chamamé son centros de reunión social construidos por la comunidad que son asociaciones de personas interesadas en las práctica del Chamamé. Estos presentan una infraestructura de ladrillo y cemento con techo de zinc. Algunos cuentan con cocina, baños, tarima y camerinos. La entrada a estos lugares tiene un valor entre los ocho y diez pesos y los encuentros ocurren los fines de semana; aunque son regulares, los mismos son anunciados por las radios comunitarias locales en el transcurso de la semana promocionando a los grupos que se presentan en cada lugar.
} 
folclore, acordeón, teatro, guaraní, entre otros; convocando a encuentros y realizando exposiciones, planificando actividades y promoviendo el acceso y participación de la población correntina y en general.

De marzo a noviembre, la Casa de Corrientes realiza una peña cada viernes de 20:30 a 1:30 horas; este encuentro convoca varias agrupaciones, en una noche pueden presentarse de cuatro a seis interpretes chamameceros. Además cada dos meses la Casa presenta sus talleres de folclore, Chamamé, guaraní y teatro. La población que asiste a estos talleres se divide en tres: los recién llegados a la $\mathrm{Capital}^{6}$, las personas de origen correntino que llevan la mayoría de su vida residiendo en Buenos Aires ${ }^{7}$ y los terceros son, personas de la capital o de otras provincias que se acercan a la Casa por diversas razones.

El trabajo de campo nos ha permitido rastrear que existen alrededor de esta institución, una serie de personas que acuden a la Casa aproximadamente tres veces a la semana; llama la atención porque en contraste con otros estudios sobre migrantes, estos dicen que en contextos migratorios, la producción de obras de danza y de música se realiza en los momentos libres o de falta de trabajo de los migrantes, construyendo tiempos liminales y marcando cortes que contrastan con el mundo cotidiano (Benza, 2005:22). Por el contrario, en el caso de los asistentes a la Casa de Corrientes, la regularidad que presentan tanto en las clases de Chamamé como los viernes en los encuentros "culturales", no responde a una relación con un estado liminal. Las indagaciones realizadas a estas personas, dan cuenta que por un lado, si son migrantes, este desplazamiento se hizo hace varios años, lo que hace pensar que su vida esta constituida en este "nuevo" entorno Bonaerense y por otro, al ya tener esta constitución, su actividad responde más a una construcción de relaciones sociales con personas que comparten sus gustos $^{8}$, que a una añoranza de su lugar de origen.

\footnotetext{
${ }^{6}$ Son pocas las personas que he encontrado entre la Casa de Corrientes y los demás centros, que sean recién llegados, sin embargo encontré un grupo de jóvenes pequeño de entre 20 y 30 años que asisten asiduamente a la Casa , donde uno de sus integrantes "el Chupa", tan solo tiene una residencia de seis meses. Dice: al otro día de haber llegado inmediatamente me contacte con la Casa y desde ese día no dejo de venir.

${ }^{7}$ Es importante señalar que en su gran mayoría las personas que asisten a la práctica del Chamamé, principalmente los que bailan, sobrepasan los 40 años; estos asistentes, llevan la mayor parte de su vida residiendo en Buenos Aires. La edad es un contraste en relación a los jóvenes, quienes son una minoría y donde su asistencia está ligada a no llevar mucho tiempo residiendo en Buenos Aires.

${ }^{8}$ Para Pirre Bourdieu, Consumo, ocio, arte, etc. son niveles de interacción de la vida cotidiana, se explican por una cosa muy obvia aunque no por ello insignificante, a saber, el gusto. El gusto limita nuestras preferencias, nuestras actitudes, ideas, acciones, pero, ¿qué es lo que limita y da forma a nuestro gusto? En principio podríamos señalar que el gusto pertenece a una orden abstracta que conforma nuestros criterios y disposiciones hacia las cosas y que en este orden, se definen las relaciones diferentes e
} 
(...) Yo asisto a la casa de corrientes, desde que está Milciades... hace 8 años, asisto porque da gusto estar, escuchar y ver a los grupos de chamamé, ver como la gente se divierte (...) viste que yo toque la otra vez, a mi me gusta venir y ayudar y si falta un músico y me piden yo me subo y toco (...) (Goyo, 2009).

El Centro Comunitario de Villa Maipú, en Lanús -Conurbano Bonaerense- es otro de los lugares donde se presenta la práctica del género; allí se realizan encuentros, o como los actores lo llaman Festivales Chamameceros. Estas reuniones son organizadas por personas que convocan músicos con cierto renombre local como por ejemplo Yoli Leiva y su conjunto; agrupación de Chamamé en la que Goyo hace la segunda voz de guitarra. Yoli es una mujer de casi cincuenta años que en el pasado se dio a conocer con el dueto de las hermanas Leiva. Conjunto que integraba con su hermana; en la actualidad es la cantante de su agrupación.

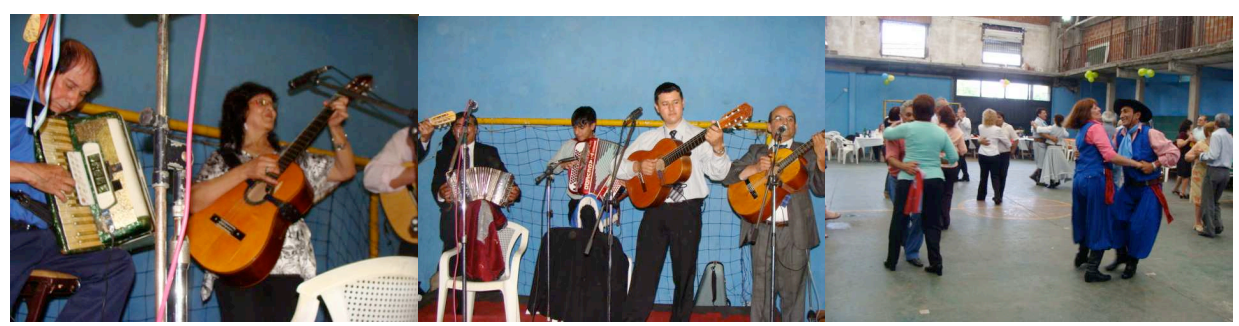

Foto: Yoli Leiva y su conjunto en el Centro de Villa Maipú

Había dejado de cantar más de 20 años, yo había grabado con mi hermana pero a mi me gustaba en las reuniones sacar mi guitarra o el acordeón y ponerme a tocar. A veces me encontraba con josecito y el me propuso volver a cantar y ya, estamos hace seis años (...) (Leiva, 2009).

El conjunto ensaya los días sábado en la casa de Yoli, en Lanús cerca del Centro Comunitario de Villa Maipú. El primer día que asistí a su ensayo, en el marco de una larga conversación, le conté que estaba aprendiendo a bailar Chamamé en la Casa de

incluso antagónicas con la cultura, según las condiciones en que hemos adquirido nuestro capital cultural y los mercados en los que podemos obtener de él, un mayor provecho. Este orden al que Bourdieu hace referencia no es otro que el habitus (Bordieu, 2006a). Es decir, es el conjunto de prácticas generadas por las condiciones de vida de los grupos sociales así como la forma en la que éstas prácticas vislumbran una relación concreta con la estructura social, esto es, el "espacio de los estilos de vida" (Bourdieu, 2006b). Estos estilos de vida, son aquellos productos del habitus que devienen en sistemas socialmente clasificados. Es decir, se puede observar como aquellas prácticas cotidianas que conforman un estilo de vida. 
Corrientes y ella me dice: ¡Ah! a mi Milciades ${ }^{9}$ me hizo un homenaje a mi carrera con el Chamamé el año pasado. Llama la atención que no solo Yoli, sino que entre los músicos y no músicos, la referencia del lugar está muy presente. El grupo está conformando por cuatro guitarras, uno o dos acordeones, dependiendo de los temas que se vayan a tocar porque Yoli, cuando toca el acordeón la agrupación se reduce a tres guitarras. Ese día, quieren enseñarme todo acerca del Chamamé. Primero Yoli pide a Josecito que toque uno rápido, me dice vení a bailar conmigo, yo te enseño. Bailamos y después pide que toquen un Cangue (Chamamé romántico), para mi es el que tiene más dificultad.

Habiendo ya superado la parte en la que me enseña a bailar, empiezo a hacer una indagación sobre cómo se toca el acordeón, principalmente a Josecito quien es parte de toda una historia en la forma en que se toca el Chamamé, dice Goyo: ten en cuenta que José es un hombre que sabe mucho, el tocó con Cocomarola ${ }^{10}$. Esto hace pensar en la legitimación que existe entre los músicos, porque si bien José es un hombre de unos setenta años tuvo, según relata, la posibilidad de tocar con grandes músicos chamameceros, la legitimación a través de cómo se debe tocar el acordeón, es parte del discurso que significa una manera, una identidad al tocar. Para José el acordeonero quien mejor toca es, quien más se acerca al sonido de los grandes... y deja deslizar la admiración que tiene por Cocomarola. Dice: el mejor sonido se consigue con el ¡acordeón de botones! A esto le pregunto ¿pero su acordeón es de teclado? y responde: yo con mis años aprendí con este y conseguí que mi sonido sea tan igual como el de teclado...pero el verdadero Chamamé se toca con el acordeón de botones.

A través del trabajo de campo, nos permitimos considerar que entre los grupos practicantes, se dan relaciones donde, cada uno ofrece un estilo particular de conocimientos vinculados a la forma de cómo aprendieron a tocar y a bailar Chamamé. Una característica a tener en cuenta en los relatos, es el sentimiento entre los actores, como producto de una construcción con hondo contenido emocional, en donde se ponen en juego roles preponderantes, determinaciones estructurales, percepciones que se tiene de las mismas y las atribuciones de una identidad por parte de los demás.

\footnotetext{
${ }^{9}$ Milciades es el director de cultura en la Casa de Corrientes y es quien coordina y sostiene los talleres y las peñas de los viernes.

${ }^{10}$ Cocomarola es uno de los músicos chamameceros mas reconocidos, sobre todo por haber compuesto lo que hoy es considerado por los practicantes como el Himno de corrientes. Km. 11.
} 
Ahora bien, en el contexto actual, las identificaciones regionales constituyen espacios simbólicos susceptibles de ser modelados en sus dimensiones y fronteras. En estos lugares se sortean expectativas que tienen los practicantes y que se presentan en la construcción de las relaciones sociales. Aunque la música, el baile y la letra del Chamamé para ellos es un referente de sus pagos de origen, estos sitios constituyen una conformación y un anclaje en este lugar que llevan habitando varias décadas.

Nuevamente, podemos mencionar como factor importante la recomposición de repertorio en función de categorías temporales, espaciales, sociales y emocionales presentes en los relatos sobre la experiencia que han tenido al vivir en Buenos Aires tanto tiempo, otorgando significado a la visita que realizan al menos una vez al año a su lugar de origen:

(...) vivo hace 48 años acá, en avellaneda soy de la ciudad de Mercedes, yo vine en busca de trabajo y con el tiempo mi vida fue cambiando, conocí a mi esposo, tuve mis hijos (...) ellos ya están grandes, yo la verdad que no me vuelvo después de tanto tiempo, mi vida está acá al lado de mi familia de mis amigos, vengo a la casa de corrientes y viajo a mercedes una vez cada año o a veces cada dos años, pero eso ya no es lo mismo, no se como decir, como yo lo recuerdo cuando era mas joven... me quedo acá(...) (A, 2009.)

Este anclaje en la Capital Federal o en el Conurbano, ha permitido que los actores construyan sus espacios y sus propias fiestas. El 22 de noviembre se celebró el día del mercedeño, la celebración debía ser paga por cada uno, el costo era de treinta pesos argentinos y en el pago se incluía un almuerzo, con la oportunidad de compartir con sus conocidos o amigos y toda una tarde de Chamamé con grupos invitados. Este día no corresponde a ninguna fiesta de la región, es algo que se construyo a través de la Casa de Corrientes, llamándose día de los merecedeños.

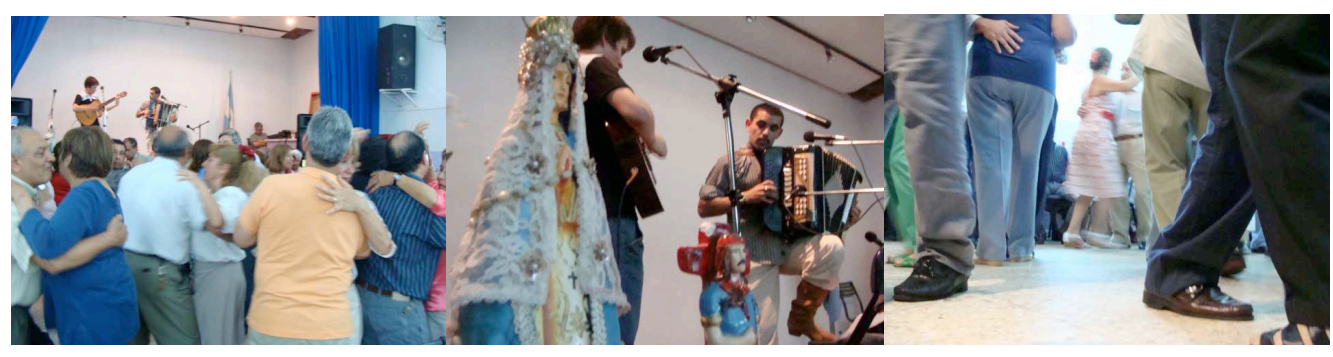


Hemos analizado hasta aquí reuniones de Chamamé que se presentan asiduamente en dos contextos - Casa de Corrientes, Centro Comunitario Villa Maipú qué, sugiero, por un lado, muestran un funcionamiento como elemento integrador de gusto y por otro, podríamos plantearnos de estos lugares, lo contextual, performático, fluido y no-esencial, acentuado en el carácter dinámico de la movilidad y la permeabilidad de los agentes y sus fronteras culturales, donde su identidad se reconfigura y se presenta como variable y no como fija.

\section{Algunas palabras finales}

Si hay algo característico de la producción contemporánea en la temática de la identidad, es el rechazo de las tradicionales formas de abordar el tema que estaban teñidas de un esencialismo obturado en procesos concretos de producción y transformación de identidad, relegando la cuestión del cambio, al quietismo de etiquetamientos inmutables y ahistóricos. Este tono de debate, pudo ser detectado con una variación en su intensidad en la mayoría de los trabajos de fines de los 80's, y principios de los 90's. A menudo se calificaba al mismo concepto de identidad como vago y tendiente a generar ambigüedades teóricas, que por un lado homologaban lo social a lo individual y por otro, no tienen en cuenta el carácter constitutivo y constituyente de las relaciones sociales en los procesos de formación de identidad ${ }^{11}$.

En este trabajo procuramos un acercamiento al planteo que se presenta al inicio, intentando dar cuenta, sobre cómo construyen los practicantes de Chamamé las relaciones sociales y su significante con la música. En cuanto a su condición de "migrantes" que en su gran mayoría residen hace varias décadas en la Capital y el Conurbano, estos han hecho de sus encuentros un vehículo para su construcción. Así mismo intentamos acercarnos al gusto -habitus-, como una forma en la que los actores construyen su práctica y le dan valor, permitiendo que las relaciones sociales se inscriban en lo simbólico. Al mismo tiempo es interesante que al pretender dar cuenta de estas relaciones, el campo nos muestra la flexibilidad en las mismas y la permeabilidad que tienen los agentes, quienes construyen un presente y quienes conforman la práctica del Chamamé hoy en Buenos Aires y el Conurbano.

\footnotetext{
${ }^{11}$ Briones: una especie de afirmación formulaica nos lleva a repetir que las identidad son construidas, contrastivas, situacionales, fragmentadas, fluidas, flexibles y disputadas.
} 
Un estudio sobre las representaciones en el origen del Chamamé entre migrantes correntinos residentes en Buenos Aires; analiza los significados de la práctica del Chamamé como expresión de continuidad, en relación a su lugar de origen, mostrando un significado de dolor, al afirmar qué, el desmembramiento de las redes familiares y sociales próximas al extrañamiento padecido en la nueva ciudad y la puja por la valorización de sus propias prácticas, propician entre los migrantes correntinos, el desarrollo de un imaginario concretizador de los lugares propios. Por otro lado, la perspectiva que se intenta abordar en este trabajo es diferente y trata de poner en cuestión, cómo las identidades son permeables, fluidas, inconsistentes y que en contraste, los actores nos muestran a través de su práctica, cómo logran adaptar y permeabilizar al "otro" con ella y cómo ellos permiten que las posibilidades brindadas por el contexto en el que viven, se conviertan en un contrapunto de construcción actual de relaciones sociales y significación del género.

Los actores representan con la música y el baile, una forma de identidad regional a la que se auto-adscriben, porque bien podrían no hacerlo y tener otras prácticas; el campo ha mostrado poco a poco una resignificación de la práctica chamamecera. En esta línea, nos proponemos un dialogo con la continuidad del trabajo empírico, asociando el hecho musical (música y baile), que nos sugiere acercarnos a la práctica de Chamamé, no solo desde la identidad; el gusto -habitusy/ o estilo de vida y el "paisaje sonoro" son también nociones a desarrollar y desde las cuales se puede observar al género.

\section{El paisaje sonoro}

Cada barrio, cada calle, cada esquina, cada espacio genera, de este modo, formas acústicas propias que constatan y relatan su existencia, dinámica y también sus transformaciones. Un rumor característico compuesto de rutinas, hábitos, acontecimientos y emergencias sonoras que configuran la vida sonoro-musical de cada lugar. Lo sonoro es en este sentido, parte integrante de la vida social: el canto de unos obreros mientras trabajan, el sonido de una pelota golpeando contra el suelo, las sirenas y las alarmas, el sonido de los motores de las motos que rugen, las conversaciones cruzadas en los lugares donde se presenta el Chamamé, las conversaciones de los vecinos en la vida cotidiana con el fondo de alguna canción o la radio comunitaria, podría decirse que hace parte de la expresión inmediata de muchos de los asistentes, como la manera que tiene esta de constituirse y definirse en si misma y como aporte a 
una configuración de representaciones sociales. Todos los sonidos son responsables de los sitios que se mezclan con otros sonidos, el ruido, el lenguaje, que dan lugar a "paisajes sonoros".

La percepción y el pensamiento para producir un sonido musical como parte de un "paisaje sonoro" es un tema relativamente nuevo principalmente en la etnomusicología. Murray Schafer, compositor y musicólogo canadiense, fue quien forjó el concepto de "paisaje sonoro" (Schafer, 1977). Según él, hay que distinguir entre dos tipos de sonidos: uno natural y otro cultural:

- El paisaje sonoro natural implica sonidos que provienen de actividades físicas o acciones de los fenómenos naturales.

- Los paisajes sonoros culturales, resultan de actividades humanas. En particular, el sonido comunicativo.

Llegar a la música a través del "paisaje sonoro" es un camino complejo. Sería demasiado simplista suponer que la música es el "paisaje sonoro". Hay que tener en cuenta la capacidad de influencia y la caracterización de los sonidos que se dan en la música. Al estudiar el conjunto de relaciones que lo sonoro-musical mantiene con la vida socio cultural, la antropología permite entender "la música como cultura"12.

Consideramos que entre los grupos musicales que interpretan Chamamé se dan relaciones de especialización, puesto que cada uno ofrece un estilo particular de conocimientos vinculado al repertorio. Ahora bien, lo sonoro-musical aparece como un escenario donde estos atributos identitarios son puestos a prueba y nos hacen preguntarnos: ¿Se inscriben en lo sonoro las diversas características de la identidad o, por el contrario son necesarios otros aparatos conceptuales para pensar la diversidad a partir de ellos? Este comportamiento -después de ser contrastado con otros parámetros "no-pertinentes" como son la línea melódica, el timbre, y el uso de determinados procedimientos antifonarios- nos ofrece una nueva explicación del acto. Los diversos

\footnotetext{
${ }^{12}$ La cultura y la identidad no tienen relación mecánica de causalidad entre ellas. La cultura puede operar con la lógica de la heterogeneidad. Para Canclini, la "cultura" se presenta como proceso social y parte de la dificultad de hablar de ella, deriva y se produce, circula y se consume en la historia social. La "cultura" no es algo que aparezca siempre de la misma manera. Un mismo objeto puede transformarse a través de los usos y reapropiaciones sociales y también al relacionarnos unos con otros, aprendemos a ser interculturales; por eso si existen transformaciones del lenguaje, la comida, el vestuario en las prácticas rutinarias en los procesos migratorios y diasporicos no implica una perdida de la identificación cultural. Por ello, las culturas son más hibridas que las identificaciones (Grimnson, 2006) En la actualidad, la cuestión de las fronteras nacionales tiene gran relevancia en los estudios antropológicos.
} 
grupos desarrollan de manera propia características sonoras que les individualizan dentro de la práctica. Aplican una imagen sonora determinada, a partir de los valores atribuidos a cada característica, y realizan una presentación (o re-presentación) de sí mismos considerada correcta y eficaz en el hecho sonoro-musical. De esta forma lo habrían entendido los participantes que han asegurado poder reconocer, a partir de una grabación los grupos de Chamamé.

Si nos limitamos, pues, al análisis de lo que llamamos estructuras pertinentes, no llegaremos a aclarar qué es lo que distingue a los diversos grupos. Según este criterio, todos estarían haciendo lo mismo. Sería cierto, ya que nos daríamos cuenta de las características generales del hecho musical, pero no lograríamos avanzar en la comprensión de los propósitos específicos qué, poniendo en funcionamiento el dispositivo previsto en la cultura, llenan de significado la práctica sonoro-musical de la Casa de Corrientes principalmente. Por el contrario, si consideramos el análisis de las estructuras pertinentes como el marco formal de partida -adecuado y necesario a una situación comunicativa precisa en una cultura- y a continuación interrogamos los usos del nivel no-pertinente que hemos convenido en llamar estilo y subgéneros del Chamamé, podemos encontrar en este nivel, los matices comunicativos que justifican el reconocimiento de la práctica como un gusto y/o estilo de vida. Estos indicios de estilo se suman a las referencias, a otras circunstancias históricas y a tomas de posición. En este momento reencontramos una vinculación directa con lo sonoro-musical en que se está desarrollando. Pero no quisiéramos fijar un hipotético modelo sonoro-musical en niveles superpuestos que muestre por un lado, las estructuras pertinentes y el estilo y por otro, lo que puede resultar del azar en la práctica específica o parte de la vida cotidiana, devenido del azar y que puede llegar a ser incontrolable. Sin embargo esto se presenta de una manera superpuesta, no de una forma separada, pudiendo ser útiles si los utilizamos como herramientas que disponen una determinada visión ordenada en la percepción de la unidad indivisible de la práctica sonoro-musical.

Creemos que esta perspectiva permite un cierto progreso en la comprensión de la práctica sonoro-musical, permitiendo un acercamiento a una imagen sonora y a unos hábitos expresivos que se ponen en funcionamiento sobre la estructura mínima del conjunto, intentando que esta imagen y estos hábitos aporten a las significaciones y el rendimiento, más allá del mero hecho de encontrarse. De esta manera podemos empezar a establecer unas ciertas vinculaciones entre la "forma" de la expresión y las interrelaciones personales que están relacionadas dentro de una situación prevista. 


\section{Referencias}

ARETZ, Isabel. El folklore musical argentino. Buenos Aires: Ricordi, 1952.

ALABARCES, Pablo. Entre Gatos y Violadores: El Rock Nacional en la Cultura Argentina. Buenos Aires: Colihue, 1992.

BOURDIEU, Pierre. La Distinción. Buenos Aires: Taurus, 2006.

BRIONES, Claudia. Formaciones de alteridad: Contextos globales, procesos nacionales y provinciales. En: Cartografías Argentinas. Políticas Indigenistas y Formaciones Provinciales de Alteridad. Buenos Aires: Antropofagia, 2005.

BRIONES, Claudia. Teorías performativas de la identidad y performatividad de las teorías" En: Tabula Rasa No.6, enero-junio. Bogotá, Colombia: Tabula Rasa, 2007. pp. 55-83.

BENZA, Silvia. Transmisión de géneros dancísticos en la migración: nuevos criterios de demarcación identitaria frente a la dilución del contexto territorial peruano" En: Cuadernos de antropología social No 22. Buenos Aires, 2005.

BRUBAKER, Royers y Frederyck Cooper. Más allá de la "identidad", en Apuntes de investigación No 7, Argentina: CECYP, 2001.

GARCÍA CANCLINI, Néstor. Culturas Hibridas. Paidós, 1990.

GIORGIS, Marta. La Virgen prestamista: la fiesta de la Virgen de Urkupiña en el boliviano gran Córdoba. Buenos Aires: Antropofagia, 2004.

CRAGNOLINI, Alejandra. El sapukai en bailes de Chamamé. En Buenos Aires y en el conurbano bonaerense. Música, emoción y tradición en migrantes correntinos.

Buenos Aires: Revista Música e Investigación, Instituto Nacional de Musicología "Carlos Vega", Año III. No 6. 2000. pp 143-152

CRAGNOLINI, Alejandra. El Chamamé en Buenos Aires. Recreación de la música tradicional y construcción de la Identidad en el contexto de migración. En: Música e Investigación, No. 1. Buenos Aires, 1997. pp. 99-115.

GRIMNSON, Alejandro. Fronteras, estados e identificaciones en el Cono Sur. En libro: Cultura, política y sociedad Perspectivas latinoamericanas. Daniel Mato. CLACSO, Consejo Latinoamericano de Ciencias Sociales, Ciudad Autónoma de Buenos Aires, Argentina. 2005. pp. 127-142. Acceso al texto completo: http://bibliotecavirtual.clacso.org.ar/ar/libros/grupos/mato/Grimson.rtf Acceso, 14 de jul. 2009.

GROSSBERG, Lawrence. Identity and Cultural Studies - Is that all there is?. En: Hall, S y du Gay, P. Questions of Cultural Identity. Londres: London, Sage Publications, 1996. pp 87 - 107.

HALL, Stuart. Notas sobre la deconstrucción de lo popular: identidades culturales y

Diáspora. Belo Horizonte: UFMG/UNESCO. 2003. pp 247-64.

MARCUS, George. Past, present and emergent identities: requirements for ethnographies of late twentieth-century modernity worldwide". En: Lash \& Friedman, Oxford: Wiley-Blackwell: Press Modernity \& Identity. 1992. pp 309-330

OCHOA, Ana María. Los géneros musicales locales ante el siglo XXI: del folclore a la industria y al patrimonio intangible”. En Músicas locales en tiempos de globalización. Buenos Aires: Norma, 2003.

SCHAFER, Raymond Murray. The Tuning of the World. New york: Random House, 1977. 


\section{Fuentes}

CERRUTI, Raúl Oscar. El Chamamé. Danza del folclore guaranítico argentino. Resistencia, Argentina: Norte Argentino, 1965.

PÉREZ BUGALlO, Rubén. El Chamamé. Buenos Aires: Ed. Del Sol, 1996. 